Check for updates

Cite this: RSC Adv., 2019, 9, 7032

\title{
Sensitive and fast fluorescence-based indirect sensing of TATP $\uparrow$
}

\author{
Shengqiang Fan, Paul L. Burn (D) * and Paul E. Shaw (D) * \\ Sensing of TATP vapours via the decomposition product, hydrogen peroxide, was achieved using \\ a fluorescence "turn-on" mechanism through conversion of boronate esters to phenoxides under basic \\ conditions in solid-state films. High sensitivity was achieved with two new fluorenylboronate esters \\ comprising either 2,4-difluorophenyl or 4-(trifluoromethyl)phenyl substituents. The key to the sensitivity \\ was the fact that the phenoxide anion products from the hydrogen peroxide oxidation absorbed at \\ longer wavelengths than the starting boronate esters. Selective excitation of the phenoxide anions \\ avoided the background fluorescence from the corresponding boronate esters. The use of the electron \\ withdrawing substituents also led to greater photostability. The derivative containing the 4- \\ (trifluoromethyl)phenyl moiety was found to give the most stable phenoxide, and demonstrated fast \\ fluorescence "turn-on" kinetics with a lower limit of detection of $\approx 2.5 \mathrm{ppb}$ in $60 \mathrm{~s}$.
}

Received 26th January 2019

Accepted 21st February 2019

DOI: 10.1039/c9ra00693a

rsc.li/rsc-advances

of fluorescence-based sensing of hydrogen peroxide, and hence TATP, in the solid-state. ${ }^{15}$ In these latter reports, the detection of the hydrogen peroxide occurs by a "turn-on" mechanism, that is, the fluorescence increases in the presence of hydrogen peroxide. It was originally thought that to achieve a high sensitivity the chromophores had to be designed so that the boronate ester was non-luminescent with the oxidised species being luminescent. ${ }^{16}$ Such a strategy is difficult as many chromophore containing boronate esters are also luminescent. Even if the sensing material is only weakly emissive it still creates sensitivity issues as it is not possible to differentiate between low levels of hydrogen peroxide, and by inference TATP, and the natural background luminescence of the material. In a recent report we recognised that the base used to accelerate the reaction of hydrogen peroxide with the boronate ester also deprotonated the formed phenol. ${ }^{15}$ While the phenols absorbed light at similar wavelengths to the boronate esters the phenolates were found to absorb at longer wavelengths. Hence, it was determined that fluorescent boronate esters could be used with high signal to noise if the excitation and detection wavelengths were selective towards the phenolate. In the initial report the change in the absorption and emission spectra was found to be dependent on the substituent ( $\mathrm{H}$ or $\mathrm{CN}$ ) attached to the parent (9,9-di-n-propyl-9H-fluoren-2-yl)-4,4,5,5-tetramethyl-1,3,2-

dioxaborolane (fluorenylboronate ester) chromophore with an electron withdrawing group favouring a red shift in the absorption and photoluminescence.

In this manuscript we report the synthesis and sensing properties of two new sensing materials comprised of 2,4difluorophenyl or 4-trifluoromethylphenyl units that are designed to increase the conjugation length of the chromophore relative to the parent fluorenylboronate ester (Fig. 1). We
Centre for Organic Photonics \& Electronics, School of Chemistry and Molecular Biosciences, The University of Queensland, Brisbane, QLD 4072, Australia. E-mail: p.burn2@uq.edu.au;p.shaw3@uq.edu.au

$\dagger$ Electronic supplementary information (ESI) available. See DOI: 10.1039/c9ra00693a 
<smiles>CCCC1(CCC)c2ccccc2-c2ccc(B3OC(C)(C)C(C)(C)O3)cc21</smiles>

Fluorenylboronate ester

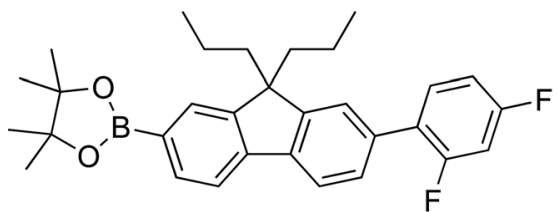

1

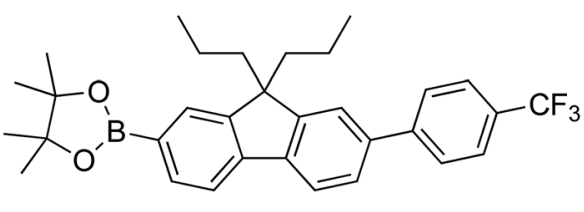

2

Fig. 1 Structures of the parent fluorenylboronate ester and the fluorinated sensing materials.

compare the photophysical properties of the materials and their respective phenols and phenoxides, showing that they can rapidly detect TATP in the solid-state. The lower limit of detection was around $\approx 2.5 \mathrm{ppb}$, which is the state-of-the-art for solid-state detection of TATP ${ }^{15}$ but in this case achieved within 60 seconds and not over the order of minutes..$^{12,16}$

\section{Results and discussion}

The synthetic strategy to the sensing materials, 2-[7-(2,4-difluorophenyl)-9,9-di- $n$-propyl-9H-fluoren-2-yl]-4,4,5,5-tetramethyl-1,3,2dioxaborolane $\mathbf{1}$ and 2-[9,9-di- $n$-propyl-7-(4-\{trifluoromethyl\} phenyl)-9H-fluoren-2-yl]-4,4,5,5-tetramethyl-1,3,2-dioxaborolane 2 is shown in Scheme 1. The first step in both syntheses was the chemoselective Suzuki-Miyaura cross-coupling reaction of 2bromo-7-iodo-9,9-di-n-propyl-9H-fluorene 3 (ref. 17) with the requisite commercially-available boronic acid ( 4 or 6 ) giving the corresponding bromide ( 5 or 7 ). Compounds 5 and 7 were isolated in yields of $78 \%$ and $90 \%$, respectively. Boronate esters 1 and 2 were then formed under palladium catalysed conditions by reaction with bis(pinacolato)diboron with a yield of $56 \%$ in both cases. The phenol derivatives for comparative purposes, 1-OH and 2-OH, were prepared by oxidation using aqueous hydrogen peroxide at room temperature and were formed in isolated yields of $86 \%$ and
$83 \%$, respectively. The fact that the phenol formation occurs in high yield is important for the success of the hydrogen peroxide sensing. Differential scanning calorimetry (DSC) at a scan rate of $50{ }^{\circ} \mathrm{C} \min ^{-1}$ showed that on the first scan both 1 and 2 had an endothermic peak at $142{ }^{\circ} \mathrm{C}$ and $171{ }^{\circ} \mathrm{C}$, respectively, that corresponded to the melting points of the individual molecules (Fig. S1†). Subsequent heating scans showed that the main thermal transition was a glass transition temperature at $52{ }^{\circ} \mathrm{C}$ for 1 and $71{ }^{\circ} \mathrm{C}$ for 2 (scan rate of $50{ }^{\circ} \mathrm{C} \mathrm{min}{ }^{-1}$ ). These results suggest that 1 and 2 are predominantly in an amorphous form after melting and relatively rapid cooling. The rapid cooling in the DSC measurement is akin to the solvent evaporation that occurs during solution processing and thus it was expected that the solution processed films used for sensing would be largely amorphous.

\section{Photophysical properties}

Before determining the efficacy of the compounds $\mathbf{1}$ and $\mathbf{2}$ for TATP sensing we characterised their photophysical properties along with the corresponding phenols and phenolates with the spectra shown in Fig. 2 and data summarised in Table 1. The addition of a substituted phenyl group shifted the maxima of the photoluminescence spectra of compounds $\mathbf{1}$ and $\mathbf{2}$ to the red $(\approx 30 \mathrm{~nm})$ with respect to the parent fluorenylboronate ester. ${ }^{15}$ In addition, the solution photoluminescence quantum yields<smiles>[R]c1ccc2c(c1)C(CCC)(CCC)c1cc(Br)ccc1-2</smiles>

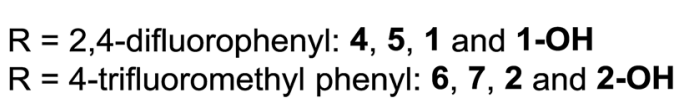<smiles>[R]c1ccc2c(c1)C(CCC)(CCC)c1cc(O)ccc1-2</smiles>

$1-\mathrm{OH}$ or $2-\mathrm{OH}$

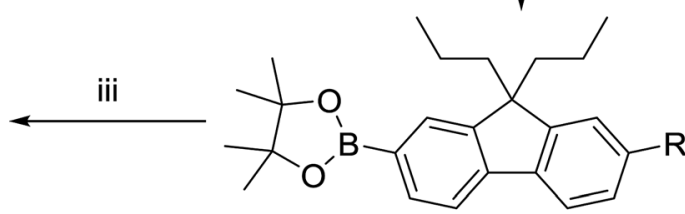

1 or 2

Scheme 1 Reactions and conditions: (i) toluene, ethanol, aqueous sodium carbonate $(2 \mathrm{M})$, tetrakis(triphenylphosphine)palladium(0), Ar, $50{ }^{\circ} \mathrm{C}$, 36-48 h; (ii) bis(pinacolato)diboron, KOAc, [1,1-bis(diphenylphosphino)ferrocene]palladium(॥) dichloride dichloromethane complex, 1,4dioxane, $\mathrm{Ar}, 105^{\circ} \mathrm{C}, 16 \mathrm{~h}$; (iii) $\mathrm{H}_{2} \mathrm{O}_{2}(30 \%)$, DMF, rt, $3 \mathrm{~h}$. 

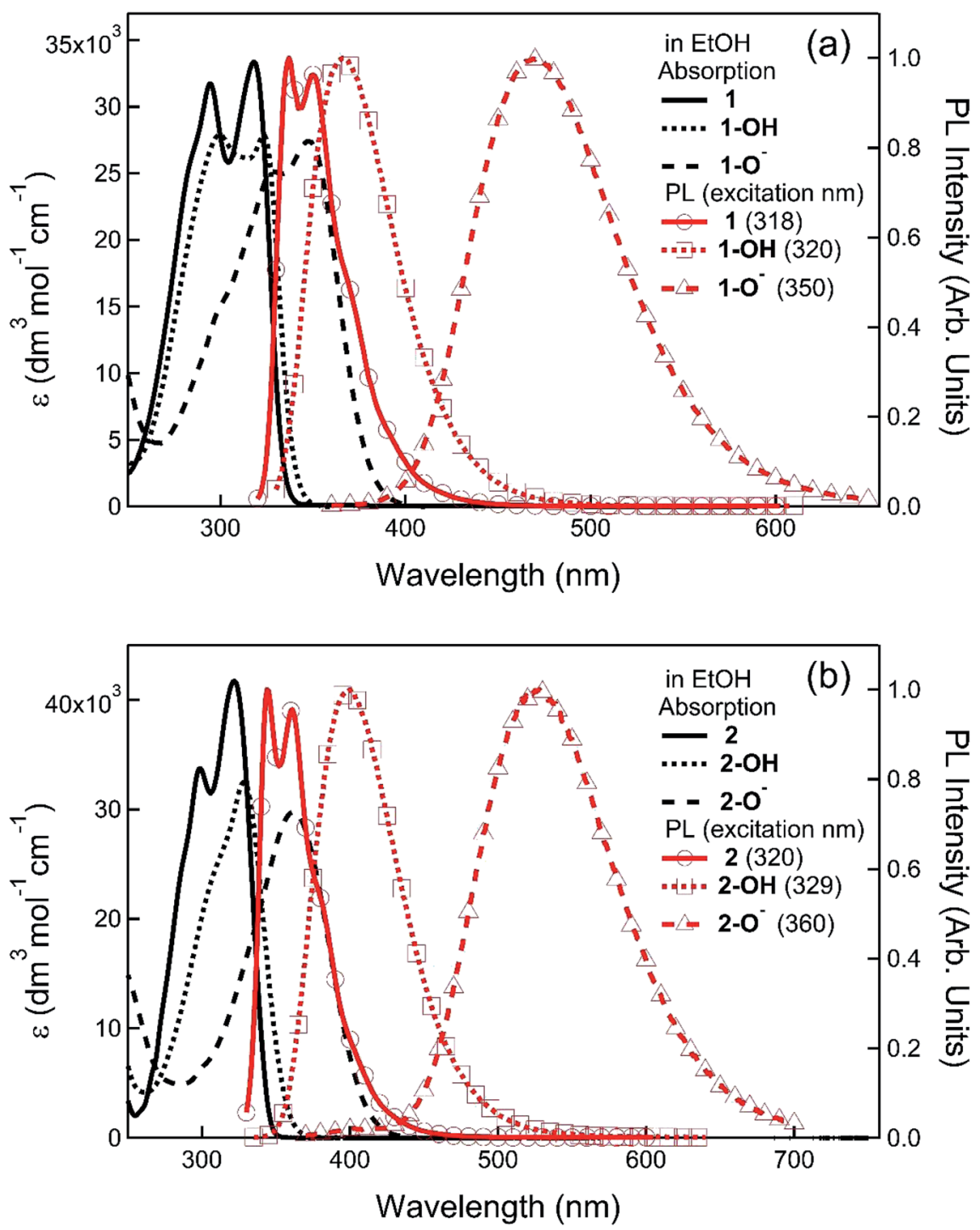

Fig. 2 The solution UV-visible absorption and photoluminescence spectra of the arylboronate esters (1 and 2), phenols (1-OH and 2-OH) and phenoxides $\left(1-\mathrm{O}^{-}\right.$and $\left.2-\mathrm{O}^{-}\right) \cdot 1-\mathrm{O}^{-}$and $2-\mathrm{O}^{-}$were obtained by mixing $1-\mathrm{OH}\left(3.4 \times 10^{-5} \mathrm{M}\right)$ or $2-\mathrm{OH}\left(2.4 \times 10^{-5} \mathrm{M}\right)$ with $(n-\mathrm{Bu})_{4} \mathrm{NOH}\left(7.3 \times 10^{-4}\right.$ $\mathrm{M})$ in ethanol.

(PLQYs) of 1 and 2 were at least $50 \%$ higher than the parent compound with 2 having a PLQY of $76 \%$. The phenols formed from 1 and 2 (1-OH and 2-OH) had similar absorption onsets

Table 1 Photophysical properties of the arylboronate esters, phenols and phenoxides in ethanol

\begin{tabular}{lll}
\hline Compound & $\begin{array}{l}\lambda_{\max } \\
(\text { emission}) / n m\end{array}$ & $\begin{array}{l}\text { Solution } \\
\text { PLQY }\end{array}$ \\
\hline $\mathbf{1}$ & 337 & 0.63 \\
$\mathbf{1 - O H}$ & 366 & 0.72 \\
$\mathbf{1 - O}$ & & 0.43 \\
$\mathbf{2}$ & 471 & 0.76 \\
$\mathbf{2 - O H}$ & 344 & 0.67 \\
$\mathbf{2 - O}$ & 400 & 0.79
\end{tabular}

${ }^{a}$ An optically dilute solution for the PLQY measurement was prepared by dissolving the phenol in ethanol containing $(n-\mathrm{Bu})_{4} \mathrm{NOH}(2.8 \times$ $\left.10^{-4} \mathrm{M}\right)$. and PLQYs to the boronate esters although the PL spectra had no phonon structure and were slightly red shifted. However, critically for the usefulness of the materials for sensing, the onset of the absorption spectra of the phenoxy species, 1-0 and $\mathbf{2 - \mathbf { O } ^ { - }}$, were at a significantly longer wavelength compared to either the corresponding boronate ester or phenol. As a consequence, it was possible to selectively excite the phenoxides and measure their PL, which also occurred at a longer wavelength to that of the boronate esters and phenols. Importantly, 1-0 ${ }^{-}$and $2-\mathbf{O}^{-}$were highly luminescent with PLQYs of $43 \%$ and $79 \%$, respectively.

\section{Solid-state detection of TATP vapours}

In the next step we determined the ability of $\mathbf{1}$ and $\mathbf{2}$ to sense TATP vapours when used in film form. Optical quality films of 1 or 2 blended with tetra- $n$-butylammonium hydroxide $\left[(n-\mathrm{Bu})_{4} \mathrm{NOH}\right]$ were formed by drop-casting from ethanol. Fig. 3 

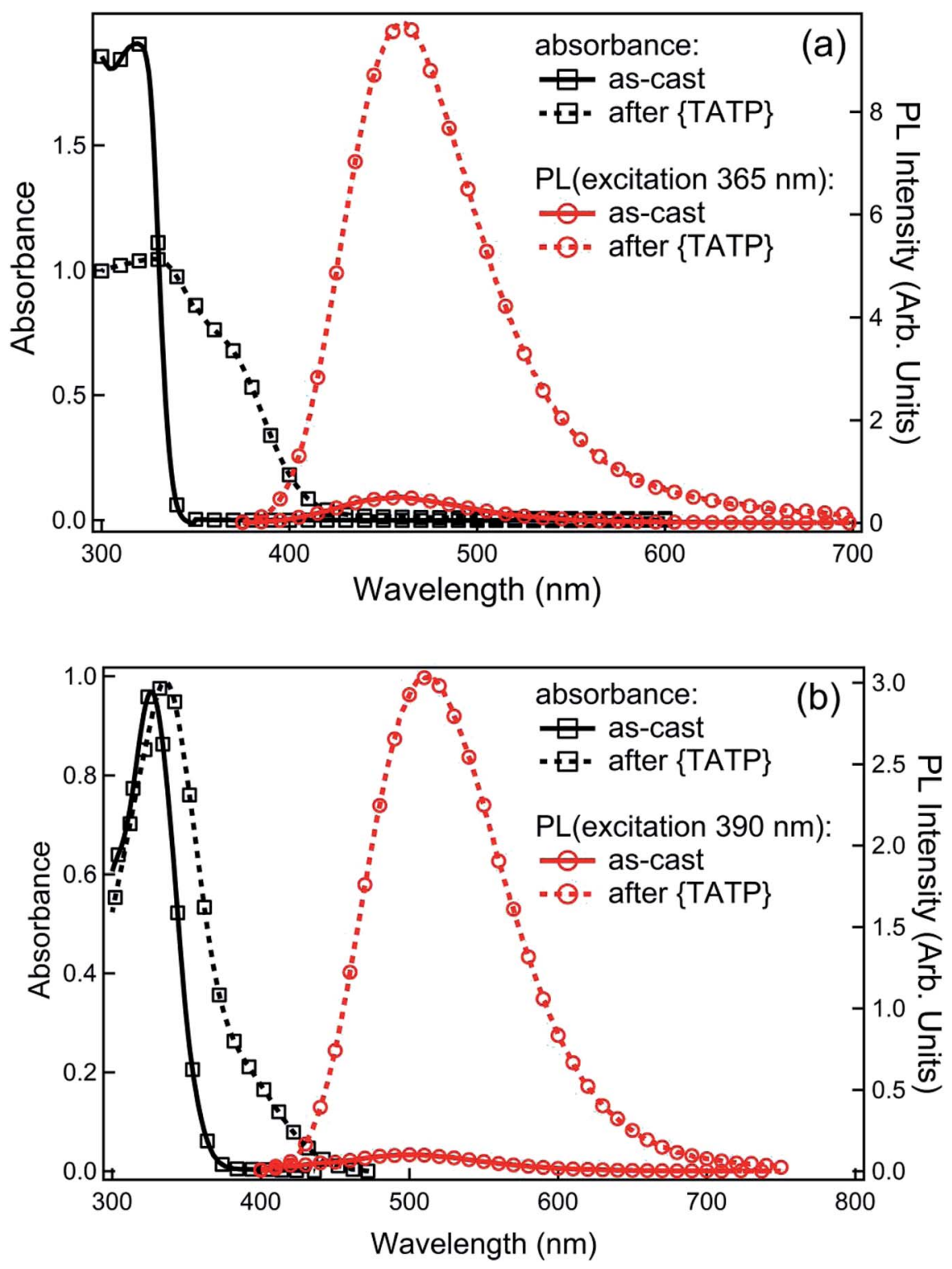

Fig. 3 UV-visible absorption and photoluminescence spectra of films on quartz substrates before and after exposure to \{TATP\}. The films were fabricated by drop-casting from a solution of boronate ester sensing material (a) 1 , or (b) 2 with $(n-\mathrm{Bu})_{4} \mathrm{NOH}(6$ equiv.).

shows the absorption spectra for the sensing film blends before and after exposure to the acid-decomposition products of TATP (denoted as $\{$ TATP $\}$ in the following discussion). In both cases there was an increase in absorption at longer wavelengths, in a similar manner to the solution measurements. On photoexcitation at a wavelength that the boronate ester did not absorb, a substantial increase in the PL signal assigned to the generated phenoxide was observed, indicating the detection of hydrogen peroxide. To prove that the phenoxide was formed we compared the absorption and PL spectra of product formed from reaction of 1 and $\{\mathrm{TATP}\}$ with that of the phenoxide $\left(\mathbf{1 - \mathbf { O } ^ { - }}\right)$ prepared directly from 1-OH. It can be seen in Fig. $\mathrm{S} 2 \uparrow$ that the spectra are identical, showing that the boronate esters are converted to the corresponding phenoxides.

For infield sensing, it is preferable to continuously illuminate the sensing film and monitor the change in the PL over time. The PL kinetics for sensing films containing 1 or 2 exposed to a range of TATP vapour concentrations are shown in Fig. 4. Each compound shows a clear response to the $\{\mathrm{TATP}\}$ vapour within seconds. The rate of the PL increase was linearly related to the TATP vapour concentration (Fig. 5). The linear relationship between the PL signal and TATP concentration enabled the limit of detection (LOD) to be estimated. By considering the PL intensity change in the first $60 \mathrm{~s}$ and comparing with three times the standard deviation $(3 \sigma)$ of the PL change in air, the LOD for films of compounds 1 and 2 were estimated to be $\approx 40$ and $\approx 2.5 \mathrm{ppb}$ for TATP, respectively. An LOD of $2.5 \mathrm{ppb}$ is an order of magnitude better than that previously reported for a cyanofluorenyl boronate ester. ${ }^{15}$

Although generally not discussed, in our previous report we showed that the PL kinetics were dependent on two reactions, that is, the formation of the phenoxide and then its subsequent 

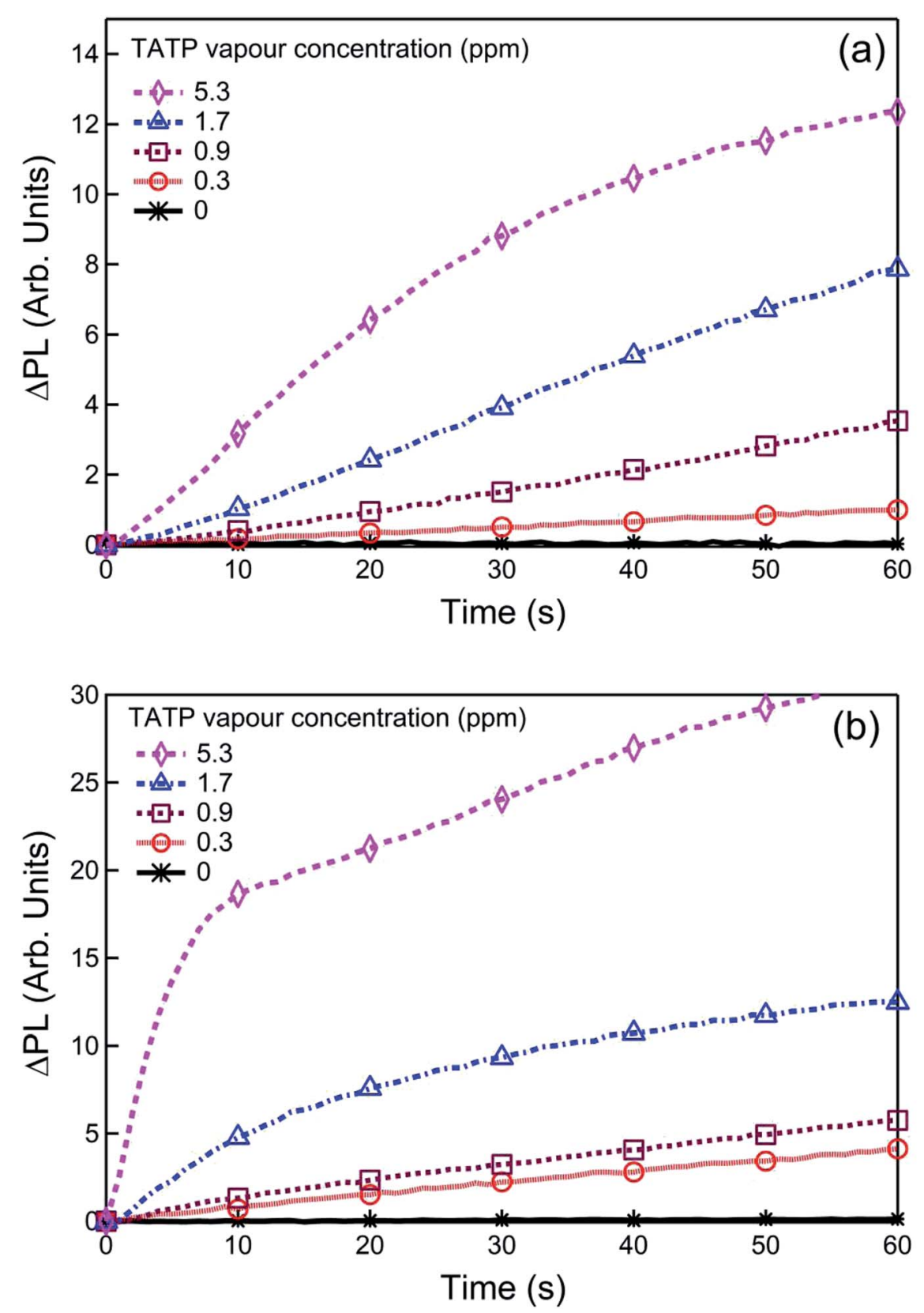

Fig. 4 Representative PL kinetics curves for sensing films at various TATP vapour concentrations. $\Delta \mathrm{PL}$ is the PL intensity change before and after exposure to $\left\{\right.$ TATP\}. The films were fabricated by drop-casting a solution of boronate ester sensing material (a) 1, or (b) 2 with ( $n$-Bu) ${ }_{4} \mathrm{NOH}(6 \mathrm{equiv}$.).

photodegradation. To understand the effect of the two processes we first followed the formation of the phenoxides in solution using UV-vis absorption kinetics (Fig. S3†) and their subsequent stability (Fig. S4†). From Fig. S3† the $t_{1 / 2}$ of the reactions of 1 or 2 with hydrogen peroxide in the presence of $(n$ $\mathrm{Bu})_{4} \mathrm{NOH}$ were determined to be similar at $15 \mathrm{~s}$ and $18 \mathrm{~s}$, respectively, and importantly both phenoxides did not appreciably degrade under the same conditions over a 5 minutes period (Fig. S4 $\dagger$ ). Substantial photodegradation would have led to a reduction in the phenoxide absorption and subsequent PL intensity. To further explore the photodegradation of phenoxides under conditions closer to those that would be used in a detection device, we measured the stability of the phenoxides in thin film form by measuring the change in the PL in the presence and absence of hydrogen peroxide under illumination. The films were formed by blending the phenol 1-OH or 2-OH with $(n-\mathrm{Bu})_{4} \mathrm{NOH}$ ( 6 equiv.) and the results are shown in Fig. 6.

Both phenoxide films show a similar slow photodegradation in air (Fig. 6), which was significantly reduced relative to that reported for the parent boronate ester. ${ }^{15}$ In order to simulate the detection scenarios where hydrogen peroxide was present, films were also exposed to hydrogen peroxide vapours (221 $\mathrm{ppm}$ ) for differing exposure times ( $0-60$ seconds) before measuring the PL kinetics under illumination. It can be seen from Fig. 6 that the decrease of the PL of the $1-\mathbf{O}^{-}$and $\mathbf{2 - \mathbf { O } ^ { - }}$ films due to photodegradation increases with increased exposure to hydrogen 

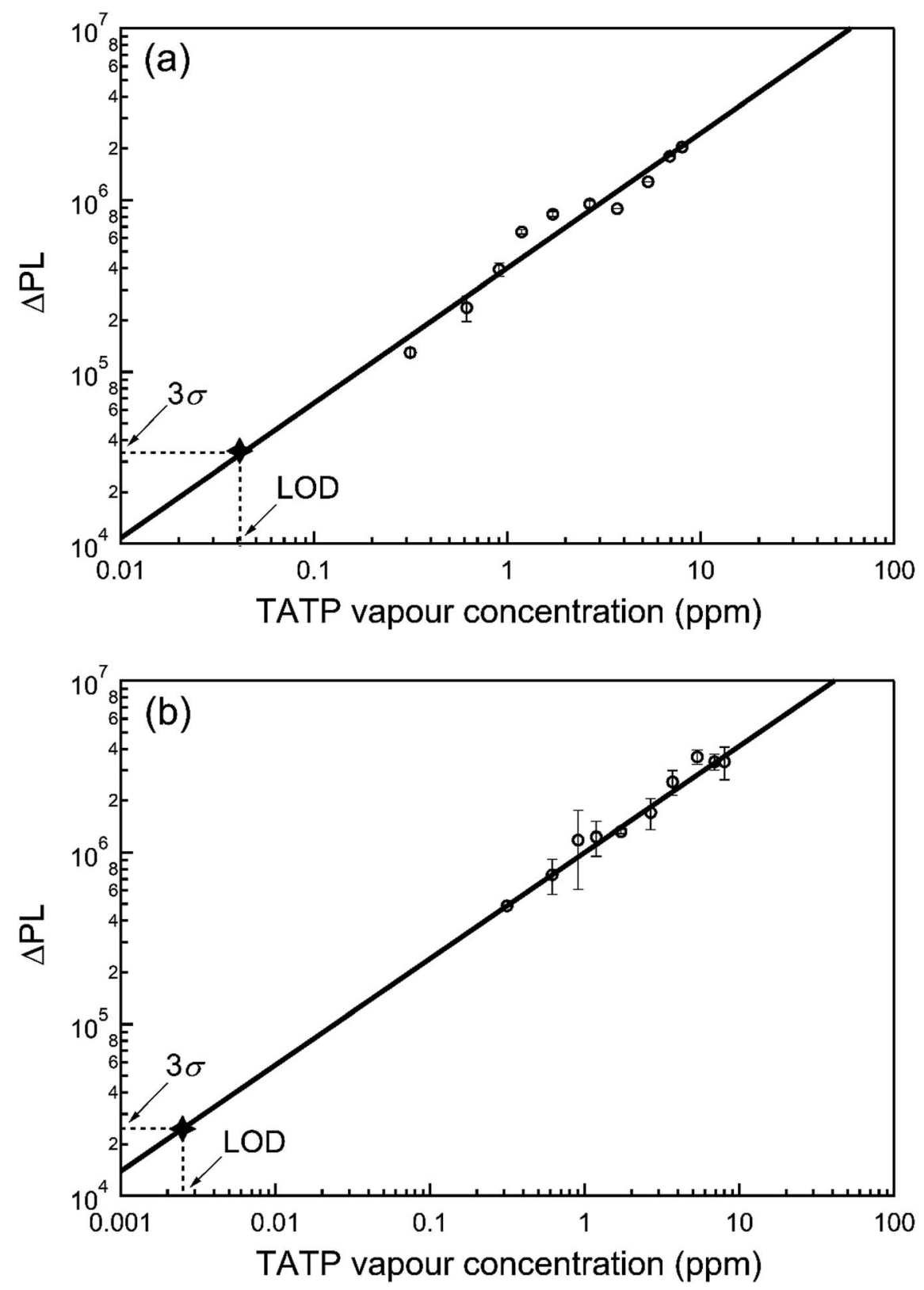

Fig. $5 \Delta \mathrm{PL}$ versus TATP vapour concentration. $\Delta \mathrm{PL}$ is the $\mathrm{PL}$ intensity change $60 \mathrm{~s}$ after exposure to $\{\mathrm{TATP}$. $3 \sigma$ is three times the standard deviation of $\triangle P L$ in air after $60 \mathrm{~s}$ (without exposure to \{TATP\}). The films were fabricated by drop-casting from a solution of (a) 1 or (b) 2 with ( $n$ $\mathrm{Bu})_{4} \mathrm{NOH}$ (6 equiv.) and the background PL of the as-deposited film was measured and subtracted from the PL measured on exposure of the film to $\{$ TATP . The errors represent the deviation of the average of at least three measurements.

peroxide. However, in both cases the decrease is less than that of the parent boronate ester ${ }^{15}$ and slower than the turn-on of the fluorescence during hydrogen peroxide detection. Thus, the addition of the electron withdrawing groups enhances the stability of the materials to photodegradation, which in turn increases the sensitivity of the sensing process as the turn-on signal is not as strongly masked by the turn-off effect of the photodegradation.

Finally, the fact that the photodegradation processes are significantly slower than the "turn-on" detection of $\{\mathrm{TATP}\}$ enabled us to compare the relative sensing kinetics of the two materials. We therefore compared the rate of change of the sensing kinetics of films of $\mathbf{1}$ and $\mathbf{2}$ with the analysis used shown in Fig. S5 $\dagger$ and the results summarised in Fig. 7. It can be seen that for all the TATP concentrations tested compound 2 has the greatest rate of PL change, which may be in part due to the greater photostability of 2-0 ${ }^{-}$(Fig. 6).

\section{Conclusions}

In summary, we have developed two new small molecule boronate ester-based sensing materials that can be used for the detection of hydrogen peroxide directly generated from the decomposition of TATP vapour. Extending the conjugation length by the addition of substituted phenyl rings red shifted 

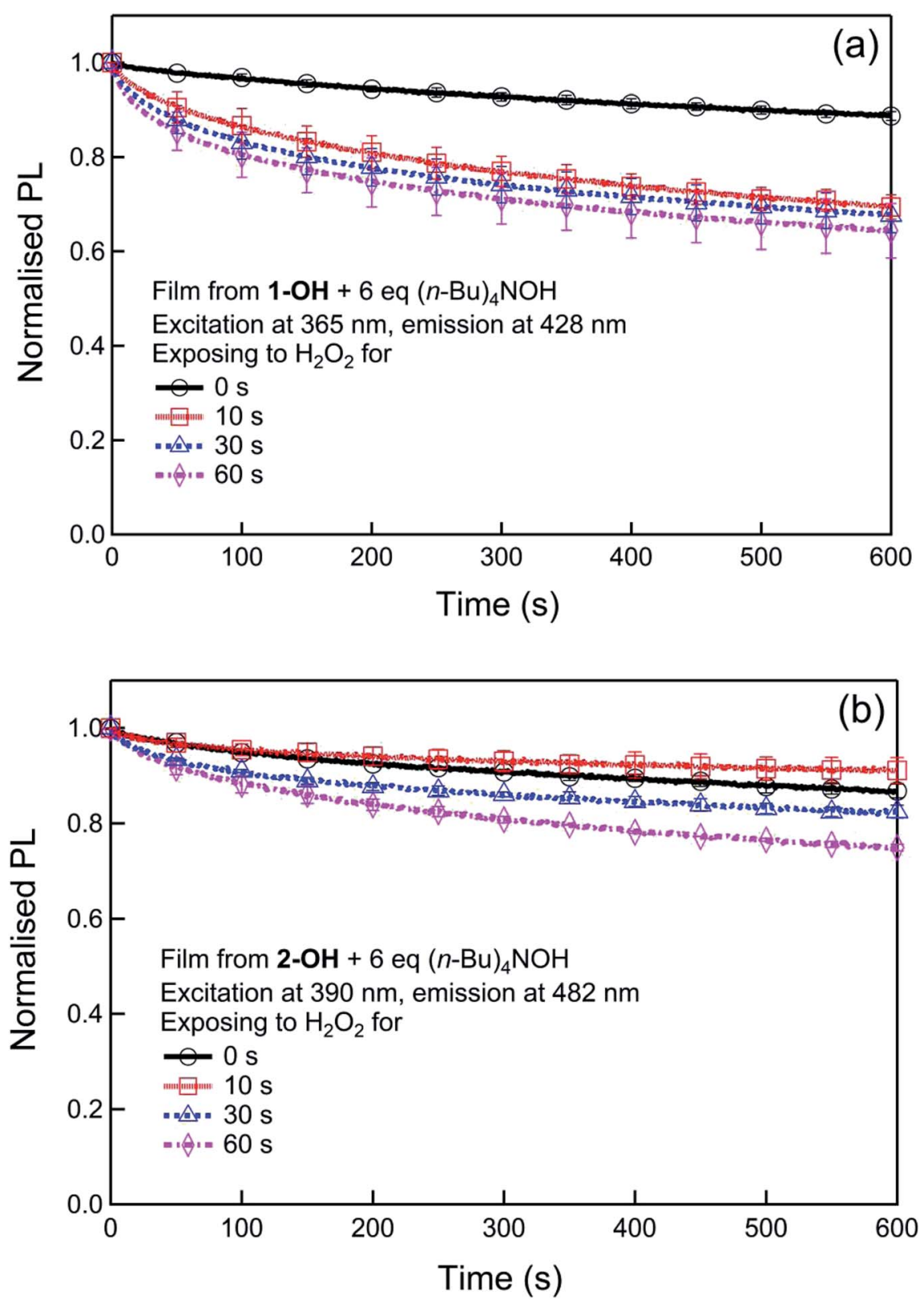

Fig. 6 Photostability of the phenoxides in air or in the presence of $\mathrm{H}_{2} \mathrm{O}_{2}$. To test the effect of $\mathrm{H}_{2} \mathrm{O}_{2}$, the films were exposed to 221 ppm $\mathrm{H}_{2} \mathrm{O}_{2}$ vapour for up to 60 seconds before measuring the photostability.

the absorption of photoluminescence spectra relative to the parent boronate ester. Importantly, the use of fluorine or trifluoromethyl substituents on the phenyl ring enhanced the sensing abilities and stabilities of the materials relative to the parent boronate ester. The material with the trifluoromethyl substituted phenyl ring had the greatest photostability and blend thin films with an organic base had a TATP limit of detection of around $2.5 \mathrm{ppb}$ after a 60 second exposure.

\section{Experimental}

\section{Materials synthesis}

All reagents were purchased from commercial sources and were used as received unless otherwise stated. Solvents for chromatography were distilled prior to use. Column chromatography was performed using Davisil LC60A 40-63 micron silica gel. Thin layer chromatography (TLC) was performed using aluminum backed silica gel 60 F254 plates. ${ }^{1} \mathrm{H}$ and ${ }^{13} \mathrm{C}$ NMR were performed using Bruker Avance 400 or $500 \mathrm{MHz}$ spectrometers in deuterated chloroform referenced to $7.26 \mathrm{ppm}$ for ${ }^{1} \mathrm{H}$ and $77.0 \mathrm{ppm}$ for ${ }^{13} \mathrm{C}, \mathrm{Fl}-\mathrm{H}=$ fluorenyl $\mathrm{H}$; $\mathrm{Pr}-\mathrm{H}=n$-propyl $\mathrm{H}$; diFPh-H $=$ 2,4-difluorophenyl $\mathrm{H} ; \mathrm{CF}_{3} \mathrm{Ph}-\mathrm{H}=4$-(trifluoromethyl)phenyl $\mathrm{H}$; $\mathrm{BE}-\mathrm{H}=$ boronate ester methyl $\mathrm{H}$. Coupling constants are given to the nearest $0.5 \mathrm{~Hz}$. UV-visible spectrophotometry was performed using a Cary 5000 UV-Vis spectrophotometer on either thin films on quartz substrates or in ethanol, with absorbance shoulders denoted as sh. FT-IR spectroscopy was performed on solid samples using a Perkin- 


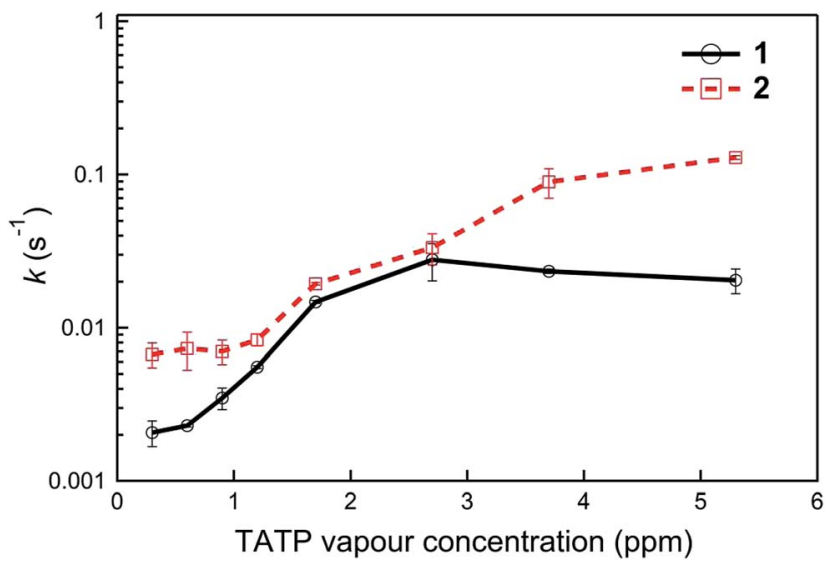

Fig. 7 PL kinetics constants, $k\left(s^{-1}\right)$, for sensing films at various TATP vapour concentrations. The films were fabricated by drop-casting a solution of boronate ester sensing material, 1 or 2 , with $(n-\mathrm{Bu})_{4} \mathrm{NOH}$ ( 6 equiv.). The errors represent the deviation of the average of at least three measurements.

Elmer Spectrum 100 FT-IR spectrometer with an ATR attachment. Melting points (MPs) were measured in a glass capillary on a Büchi B-545 melting point apparatus and are uncorrected. Microanalyses were performed using a Carlo Erba NA 1500 Elemental Analyzer. Low resolution electrospray ionisation (ESI) mass spectra were acquired on a Bruker Esquire HCT (High Capacity 3D ion trap) instrument with a Bruker ESI source. Thermal transitions were determined using a Perkin-Elmer Diamond Differential Scanning Calorimeter. Thermal gravimetric analysis was undertaken using a Perkin-Elmer STA 6000 Simultaneous Thermal Analyzer. Thermal decomposition temperatures $\left(T_{5 \%}\right)$ are reported as the temperature corresponding to a $5 \%$ mass loss.

2-Bromo-7-(2,4-difluorophenyl)-9,9-di- $\boldsymbol{n}$-propyl-9H-fluorene 5.

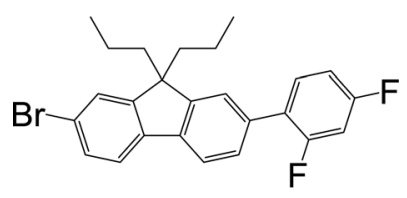

5

A mixture of (2,4-difluorophenyl)boronic acid 4 (0.32 g, 2.0 mmol), 2-bromo-7-iodo-9,9-di- $n$-propyl-9H-fluorene 3 (ref. 17) (1.1 g, $2.4 \mathrm{mmol})$, aqueous sodium carbonate $(2 \mathrm{M}, 5 \mathrm{~mL})$, toluene $(80 \mathrm{~mL})$ and ethanol $(20 \mathrm{~mL})$ was deoxygenated by applying a vacuum and backfilling with argon six times. Then tetrakis(triphenylphosphine)palladium(0) $(0.12 \mathrm{~g}, 0.10 \mathrm{mmol})$ was added and the reaction vessel was deoxygenated again by applying a vacuum and backfilling with argon six times. The mixture was stirred under argon in an oil bath held at $50{ }^{\circ} \mathrm{C}$ for $48 \mathrm{~h}$. After being allowed to cool to room temperature, ethyl acetate $(100 \mathrm{~mL})$ and water $(100 \mathrm{~mL})$ were added and the organic and aqueous layers separated. The aqueous phase was extracted with ethyl acetate $(3 \times 50 \mathrm{~mL})$, and the combined organic phases were washed with brine $(2 \times 100 \mathrm{~mL})$, dried over anhydrous magnesium sulfate, and filtered. The filtrate was collected and the solvent removed. The residue was purified by column chromatography over silica using ethyl acetate : petroleum ether $(1: 19)$ as eluent to afford the product as a white solid (0.69 g, 78\%). Mp 102-103 ${ }^{\circ} \mathrm{C}$. Elemental analysis (\%) calcd for $\mathrm{C}_{26} \mathrm{H}_{24} \mathrm{BrF}_{3} \mathrm{C}$ 68.0, $\mathrm{H}$ 5.25; found: C 67.8, H 5.3. $\lambda_{\max }(-$ dichloromethane)/nm: $285 \mathrm{sh}\left(\log \varepsilon / \mathrm{dm}^{3} \mathrm{~mol}^{-1} \mathrm{~cm}^{-1} 4.45\right)$, 293 (4.50), 317 (4.49). ${ }^{1} \mathrm{H}$ NMR ( $\left.\delta, 400 \mathrm{MHz}, \mathrm{CDCl}_{3}\right)$ : 0.67-0.74 $(10 \mathrm{H}, \mathrm{m}, \mathrm{Pr}-\mathrm{H}), 1.90-2.02(4 \mathrm{H}, \mathrm{m}, \mathrm{Pr}-\mathrm{H}), 6.91-7.01(2 \mathrm{H}, \mathrm{m}$, diFPh-H), 7.44-7.50 (5H, m, diFPh-H and Fl-H), $7.58(1 \mathrm{H}, \mathrm{d}, J=$ 8.0, Fl-H), 7.72 (1H, dd, $J=1.5, J=7.0, \mathrm{Fl}-\mathrm{H}) .{ }^{13} \mathrm{C}$ NMR $(\delta, 100$ $\mathrm{MHz}, \mathrm{CDCl}_{3}$ ): 14.4, 17.2, 42.5, 55.7, 104.4 (dd, $J=25.5$ \& 26.5), $111.5(\mathrm{dd}, J=4.0$ \& 21.0), 119.8, 121.1 (6), $121.2(5), 123.5$ (d, $J=$ 3.0), 125.6 (dd, $J=3.5 \& 13.0), 126.2,127.8(\mathrm{~d}, J=2.5), 130.0$, $131.4(\mathrm{dd}, J=5.0 \& 9.0), 134.1,139.6(\mathrm{~d}, J=1), 159.8(\mathrm{dd}, J=12.0$ $\& 248.5), 162.2$ (dd, $J=12.0$ \& 247.5).

2-[7-(2,4-Difluorophenyl)-9,9-di-n-propyl-9H-fluoren-2-yl]4,4,5,5-tetramethyl-1,3,2-dioxaborolane 1 .

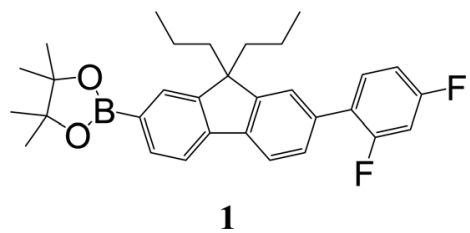

A mixture of 5 (0.59 g, $1.3 \mathrm{mmol})$, bis(pinacolato)diboron $(0.51 \mathrm{mg}, 2.0 \mathrm{mmol})$, potassium acetate (0.39 g, $4.0 \mathrm{mmol})$, [1,1bis(diphenylphosphino)ferrocene]palladium(II) dichloride dichloromethane complex (30 mg, $0.04 \mathrm{mmol}$ ) and 1,4-dioxane $(20 \mathrm{~mL})$ was stirred under argon in an oil bath held at $105{ }^{\circ} \mathrm{C}$ for $16 \mathrm{~h}$. The mixture was allowed to cool to room temperature and then the solvent was removed under reduced pressure. Water (50 $\mathrm{mL})$ and dichloromethane $(50 \mathrm{~mL})$ were added to the reaction mixture and the organic phase was separated. The aqueous layer was extracted with dichloromethane $(3 \times 50 \mathrm{~mL})$. The dichloromethane extracts were combined, washed with brine $(2 \times 50$ $\mathrm{mL}$ ), dried over anhydrous sodium sulfate, and filtered. The filtrate was collected and the solvent removed. The residue was purified by column chromatography over silica using dichloromethane : petroleum ether $(1: 3)$ as eluent to give a white solid (0.36 g, 56\%). Mp 142-143 ${ }^{\circ} \mathrm{C}$; mp (DSC) $=142{ }^{\circ} \mathrm{C}$ (first heating scan - scan rate $\left.50{ }^{\circ} \mathrm{C} \min ^{-1}\right) . T_{\mathrm{g}}=52{ }^{\circ} \mathrm{C}$ (second heating scan DSC scan rate $50{ }^{\circ} \mathrm{C} \min ^{-1}$ ). $T_{5 \%}=284{ }^{\circ} \mathrm{C}$ (sublimed). Elemental analysis (\%) calcd for $\mathrm{C}_{31} \mathrm{H}_{35} \mathrm{BF}_{2} \mathrm{O}_{2} \mathrm{C} 76.2, \mathrm{H}$ 7.2; found: $\mathrm{C} 76.2, \mathrm{H}$ 7.3. $\lambda_{\max }\left(\right.$ dichloromethane)/nm: $286 \mathrm{sh}\left(\log \varepsilon / \mathrm{dm}^{3} \mathrm{~mol}^{-1} \mathrm{~cm}^{-1}\right.$ 4.40), $295 \quad$ (4.47), $319 \quad$ (4.51). $\lambda_{\max }$ (fluorescence) (dichloromethane)/nm: 339, 353, 371 sh. ${ }^{1} \mathrm{H}$ NMR $(\delta, 500 \mathrm{MHz}$, $\left.\mathrm{CDCl}_{3}\right)$ : 0.65-0.71 (10H, m, Pr-H), 1.39 (12H, s, BE-H), 1.94-2.06 $(4 \mathrm{H}, \mathrm{m}, \mathrm{Pr}-\mathrm{H}), 6.91-7.00(2 \mathrm{H}, \mathrm{m}, \operatorname{diFPh}-\mathrm{H}), 7.45-7.50(3 \mathrm{H}, \mathrm{m}$, diFPh-H and Fl-H), $7.72(1 \mathrm{H}, \mathrm{dd}, J=0.5, J=7.5$, Fl-H), 7.76-7.78 $(2 \mathrm{H}, \mathrm{m}, \mathrm{Fl}-\mathrm{H}), 7.82$ (1H, dd $J=1.0, J=7.5, \mathrm{Fl}-\mathrm{H}) .{ }^{13} \mathrm{C} \operatorname{NMR}(\delta, 100$ $\left.\mathrm{MHz}, \mathrm{CDCl}_{3}\right): 14.4,17.2,24.9,42.5,55.4,83.7,104.4(\mathrm{dd}, J=25.0$, $J=26.5), 111.5(\mathrm{dd}, J=3.5, J=21.0), 119.1,120.1,123.5(\mathrm{~d}, J=$ 3.0), 125.8 (dd, $J=4.0, J=13.5$ ), 127.6 (d, $J=2.5$ ), 128.9, 131.5 $(\mathrm{dd}, J=5.0, J=9.0), 133.8,134.1,140.5,143.5,150.2,151.6,159.8$ 
$(\mathrm{dd}, J=11.5, J=249.0), 162.2(\mathrm{dd}, J=12.0, J=247.0) . \mathrm{m} / z\left[\mathrm{ESI}^{+}\right]$: expected $489.3\left([\mathrm{M}+\mathrm{H}]^{+}\right)$, found: $489.1\left([\mathrm{M}+\mathrm{H}]^{+}\right)$.

7-(2,4-Difluorophenyl)-9,9-di-n-propyl-9H-fluoren-2-ol 1-OH.

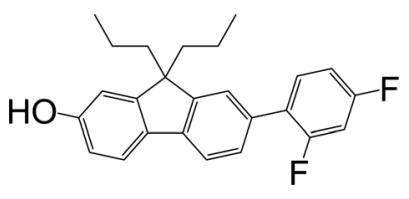

1-OH

Aqueous hydrogen peroxide $(30 \%, 3 \mathrm{~mL})$ was added to a solution of 1 (75 mg, $0.15 \mathrm{mmol}$ ) in $\mathrm{N}, \mathrm{N}$-dimethylformamide (10 $\mathrm{mL})$. The mixture was stirred at room temperature for $3 \mathrm{~h}$. Then ethyl acetate $(30 \mathrm{~mL})$ was added and the mixture was washed with hydrochloric acid $(1 \mathrm{M}, 2 \times 50 \mathrm{~mL})$ and brine $(3 \times 30 \mathrm{~mL})$, and then dried over anhydrous sodium sulfate, and filtered. The filtrate was collected and the solvent removed. The residue was purified by column chromatography over silica using dichloromethane as eluent to give a white solid (50 mg, 86\%). Mp $170-171{ }^{\circ} \mathrm{C}$. Elemental analysis (\%) calcd for $\mathrm{C}_{25} \mathrm{H}_{24} \mathrm{~F}_{2} \mathrm{O} \mathrm{C}$ 79.3, H 6.4; found: $\mathrm{C}$ 79.4, $\mathrm{H}$ 6.4. IR $\nu_{\max } / \mathrm{cm}^{-1} 3281(\mathrm{OH})$. $\lambda_{\max }$ (dichloromethane)/nm: $297\left(\log \varepsilon / \mathrm{dm}^{3} \mathrm{~mol}^{-1} \mathrm{~cm}^{-1} 4.39\right)$, $309 \mathrm{sh}$ (4.33), 322 (4.37). $\lambda_{\max }($ fluorescence) (dichloromethane)/ nm: 356. ${ }^{1} \mathrm{H}$ NMR $\left(\delta, 500 \mathrm{MHz}, \mathrm{CDCl}_{3}\right): 0.67-0.75(10 \mathrm{H}, \mathrm{m}, \mathrm{Pr}-$ $\mathrm{H}), 1.88-2.00$ (4H, m, Pr-H), 4.98 (1H, br, OH-H), 6.81 (1H, dd, $J=2.0, J=8.0$, Fl-H), $6.85(1 \mathrm{H}, \mathrm{d}, J=1.5, \mathrm{Fl}-\mathrm{H}), 6.91-6.99(2 \mathrm{H}$, $\mathrm{m}$, diFPh-H), 7.43-7.49 (3H, m, diFPh-H \& Fl-H), 7.58 (1H, d, $J=$ 8, Fl-H), $7.64\left(1 \mathrm{H}, \mathrm{d}, J=8\right.$, Fl-H). ${ }^{13} \mathrm{C} \mathrm{NMR}\left(\delta, 125 \mathrm{MHz}, \mathrm{CDCl}_{3}\right)$ : $14.4,17.2,42.8,55.3,104.3(\mathrm{dd}, J=26.0, J=26.0), 110.2,111.4$ $(\mathrm{dd}, J=4.0, J=20.5), 114.1,118.8,120.7,123.3(\mathrm{~d}, J=3.0), 125.9$ $(\mathrm{dd}, J=4.0, J=13.5), 127.6(\mathrm{~d}, J=2.5), 131.4(\mathrm{dd}, J=5.0, J=$ 9.5), 132.5 133.7, 140.6, 150.4, 153.5, 155.5, 159.7 (dd, $J=12.0, J$ $=248.5), 162.0(\mathrm{dd}, J=11.5, J=247.0) \cdot \mathrm{m} / z$ [ESI $\left.{ }^{-}\right]$: expected $377.2\left([\mathrm{M}-\mathrm{H}]^{-}\right)$, found: $377.1\left([\mathrm{M}-\mathrm{H}]^{-}\right)$.

2-Bromo-9,9-di-n-propyl-7-[4-(trifluoromethyl)phenyl]-9Hfluorene 7 .

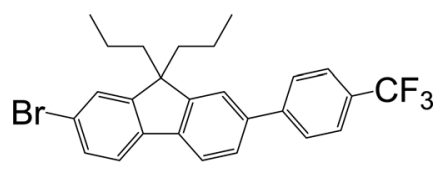

7

A mixture of [4-(trifluoromethyl)phenyl]boronic acid $6(0.48 \mathrm{~g}$, $2.5 \mathrm{mmol}$ ), 2-bromo-7-iodo-9,9-di- $n$-propyl-9H-fluorene 3 (ref. 17) $(1.4 \mathrm{~g}, 3.0 \mathrm{mmol})$, aqueous sodium carbonate $(2 \mathrm{M}, 25 \mathrm{~mL})$, toluene $(100 \mathrm{~mL})$, and ethanol $(25 \mathrm{~mL})$ was deoxygenated by applying a vacuum and backfilling with argon six times. Then tetrakis(triphenylphosphine)palladium(0) (146 mg, $0.13 \mathrm{mmol}$ ) was added and the reaction vessel was deoxygenated again by applying a vacuum and backfilling with argon six times. The mixture was then stirred under argon in an oil bath held at $50{ }^{\circ} \mathrm{C}$ for $36 \mathrm{~h}$. After being allowed to cool to room temperature, ethyl acetate $(50 \mathrm{~mL})$ and water $(50 \mathrm{~mL})$ were added and the organic and aqueous layers were separated. The aqueous phase was extracted with ethyl acetate $(3 \times 50 \mathrm{~mL})$, and the combined organic phases were washed with brine $(2 \times 100 \mathrm{~mL})$, dried over anhydrous sodium sulfate, and filtered. The filtrate was collected and the solvent removed. The residue was purified by column chromatography over silica using ethyl acetate : petroleum ether $(1: 19)$ as eluent to afford the product as a white solid (1.1 g, 90\%). Mp 141-142 ${ }^{\circ} \mathrm{C}$. Elemental analysis (\%) calcd for $\mathrm{C}_{26} \mathrm{H}_{24} \mathrm{BrF}_{3} \mathrm{C}$ 66.0, $\mathrm{H}$ 5.1; found: $\mathrm{C}$ 65.9, $\mathrm{H}$ 4.9. $\lambda_{\max }(-$ dichloromethane)/nm: $288 \mathrm{sh}\left(\log \varepsilon / \mathrm{dm}^{3} \mathrm{~mol}^{-1} \mathrm{~cm}^{-1} 4.38\right)$, 300 (4.48), 321 (4.55). ${ }^{1} \mathrm{H}$ NMR ( $\left.\delta, 400 \mathrm{MHz}, \mathrm{CDCl}_{3}\right): 0.68-0.74$ (10H, m, Pr-H), 1.93-2.04 (4H, m, Pr-H), $7.48(1 \mathrm{H}, \mathrm{dd}, J=2.0, J=$ 8.0, Fl-H), 7.51 (1H, d, $J=1.5$, Fl-H), 7.55 (1H, d, $J=1.0, \mathrm{Fl}-\mathrm{H})$, $7.58(1 \mathrm{H}, \mathrm{dd}, J=1.5, J=8.0$, Fl-H), $7.59(1 \mathrm{H}, \mathrm{d}, J=8.0, \mathrm{Fl}-\mathrm{H})$, 7.71 and $7.76\left(4 \mathrm{H}, \mathrm{AA}^{\prime} \mathrm{BB}^{\prime}, \mathrm{CF}_{3} \mathrm{Ph}-\mathrm{H}\right), 7.75(1 \mathrm{H}, \mathrm{d}, J=8.0$, Fl$\mathrm{H}) .{ }^{13} \mathrm{C} \mathrm{NMR}\left(\delta, 100 \mathrm{MHz}, \mathrm{CDCl}_{3}\right): 14.4,17.2,42.6,55.7,120.2$, 121.2, 121.4, 121.6, $124.3\left(\mathrm{q},{ }^{1} J_{\mathrm{C}-\mathrm{F}}=270.0\right), 125.7\left(\mathrm{q},{ }^{3} J_{\mathrm{C}-\mathrm{F}}=3.5\right)$, 126.3, 126.4, 127.4, $129.3\left(\mathrm{q},{ }^{2} J_{\mathrm{C}-\mathrm{F}}=32.5\right), 130.1,139.0,139.4$, 140.2, 144.9, 151.3, 153.3.

2-[9,9-Di-n-propyl-7-(4-\{trifluoromethyl $\}$ phenyl)-9H-fluoren2-yl]-4,4,5,5-tetramethyl-1,3,2-dioxaborolane 2 .

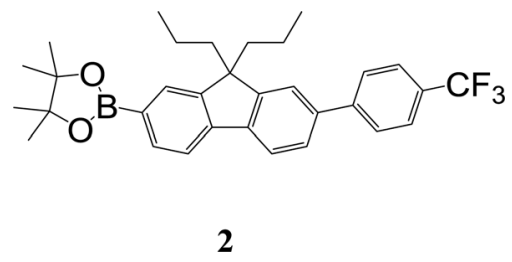

A mixture of $7(0.47 \mathrm{~g}, 1.0 \mathrm{mmol})$, bis(pinacolato)diboron $(0.38 \mathrm{~g}, 1.5 \mathrm{mmol})$, potassium acetate $(0.29 \mathrm{~g}, 3.0 \mathrm{mmol}),[1,1-$ bis(diphenylphosphino)ferrocene]palladium(II) dichloride dichloromethane complex (22 mg, $0.03 \mathrm{mmol}$ ) and 1,4-dioxane $(10 \mathrm{~mL})$ was deoxygenated and stirred under argon in an oil bath held at $105{ }^{\circ} \mathrm{C}$ for $16 \mathrm{~h}$. The mixture was allowed to cool to room temperature and then the solvent removed under reduced pressure. Water $(50 \mathrm{~mL})$ and ethyl acetate $(50 \mathrm{~mL})$ were added and the organic phase was separated. The aqueous layer was extracted with ethyl acetate $(3 \times 30 \mathrm{~mL})$. The ethyl acetate extracts were combined, washed with brine $(2 \times 50 \mathrm{~mL})$, dried over anhydrous sodium sulfate, and filtered. The filtrate was collected and the solvent removed. The residue was purified by column chromatography over silica using dichloromethane : petroleum ether $(1: 3)$ as eluent to give the product as a white solid $(0.29 \mathrm{~g}, 56 \%)$. Mp 168-169 ${ }^{\circ} \mathrm{C}$; mp $(\mathrm{DSC})=$ $171{ }^{\circ} \mathrm{C}$ (first heating scan - scan rate $50{ }^{\circ} \mathrm{C} \min ^{-1}$ ). $T_{\mathrm{g}}=71{ }^{\circ} \mathrm{C}$ (second heating scan - DSC scan rate $50{ }^{\circ} \mathrm{C} \mathrm{min}^{-1}$ ). $T_{5 \%}=$ $287{ }^{\circ} \mathrm{C}$ (sublimed). Elemental analysis (\%) cal. For $\mathrm{C}_{32} \mathrm{H}_{36} \mathrm{BF}_{3} \mathrm{O}_{2}$ C, 73.85; H, 7.0. Found: $\mathrm{C}, 73.7 ; \mathrm{H}, 7.0 . \lambda_{\max }($ dichloromethane)/ $\mathrm{nm}: 290 \mathrm{sh}$ (log $\varepsilon / \mathrm{dm}^{3} \mathrm{~mol}^{-1} \mathrm{~cm}^{-1} 4.39$ ), 300 (4.49), 323 (4.60). $\lambda_{\max }$ (fluorescence) (dichloromethane)/nm: 350, 365, 383 sh. ${ }^{1} \mathrm{H}$ NMR $\left(\delta, 500 \mathrm{MHz}, \mathrm{CDCl}_{3}\right)$ : 0.67-0.70 (10H, m, Pr-H), 1.40 (12H, s, BE-H), 1.97-2.08 (4H, m, Pr-H), 7.56 (1H, brm, Fl-H), $7.58(1 \mathrm{H}, \mathrm{dd}, J=1.5, J=8.0, \mathrm{Fl}-\mathrm{H}), 7.71$ and $7.76\left(4 \mathrm{H}, \mathrm{AA}^{\prime} \mathrm{BB}^{\prime}\right.$, $\left.\mathrm{CF}_{3} \mathrm{Ph}-\mathrm{H}\right), 7.73(1 \mathrm{H}, \mathrm{d}, J=8.0$, Fl-H), $7.78(1 \mathrm{H}, \mathrm{s}, \mathrm{Fl}-\mathrm{H}), 7.80(1 \mathrm{H}$, $\mathrm{d}, J=7.5$, Fl-H), 7.83 (1H, d, $J=7$, Fl-H). ${ }^{13} \mathrm{C} \mathrm{NMR}(\delta, 100 \mathrm{MHz}$, $\left.\mathrm{CDCl}_{3}\right)$ : 14.4, 17.2, 24.9, 42.6, 55.5, 83.8, 119.2, 120.5, 121.7, $124.3\left(\mathrm{q},{ }^{1} J_{\mathrm{C}-\mathrm{F}}=270.2\right), 125.7\left(\mathrm{q},{ }^{3} J_{\mathrm{C}-\mathrm{F}}=3.6\right), 126.1,127.5,128.9$, 
$129.1\left(\mathrm{q},{ }^{2} J_{\mathrm{C}-\mathrm{F}}=31.4\right), 133.9,139.0,141.1,143.3,145.1,150.2$, 152.2. $\mathrm{m} / \mathrm{z}\left[\mathrm{ESI}^{+}\right]$: expected $521.3\left([\mathrm{M}+\mathrm{H}]^{+}\right)$, found: $521.1([\mathrm{M}+$ $\left.\mathrm{H}]^{+}\right)$.

7-(2,4-Difluorophenyl)-9,9-di-n-propyl-9H-fluoren-2-ol 2-OH.

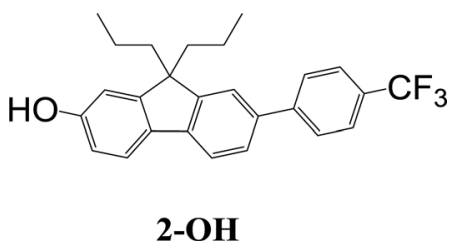

Aqueous hydrogen peroxide $(30 \%, 3 \mathrm{~mL})$ was added to a solution of 2 (61 mg, $0.12 \mathrm{mmol})$ in $N, N$-dimethylformamide $(10 \mathrm{~mL})$. The mixture was stirred at room temperature for $3 \mathrm{~h}$ before ethyl acetate $(30 \mathrm{~mL})$ was added. The mixture was washed with hydrochloric acid $(1 \mathrm{M}, 2 \times 50 \mathrm{~mL})$ and brine $(3 \times 30 \mathrm{~mL})$, then dried over anhydrous sodium sulfate and filtered. The filtrate was collected and the solvent removed. The residue was purified by column chromatography over silica using dichloromethane as eluent to give the product as a white solid (40 mg, 83\%). Mp 168$169{ }^{\circ} \mathrm{C}$. Elemental analysis (\%) calcd for $\mathrm{C}_{26} \mathrm{H}_{25} \mathrm{~F}_{3} \mathrm{O}$ C 76.1, $\mathrm{H}$ 6.1. Found: $\mathrm{C}$ 76.1, H 6.1. IR $\nu_{\max } / \mathrm{cm}^{-1} 3277$ (OH). $\lambda_{\max }(-$ dichloromethane)/nm: $310 \mathrm{sh}\left(\log \varepsilon / \mathrm{dm}^{3} \mathrm{~mol}^{-1} \mathrm{~cm}^{-1} 4.43\right), 326$ (4.52). $\lambda_{\max }\left(\right.$ fluorescence) (dichloromethane)/nm: $385 .{ }^{1} \mathrm{H}$ NMR $\left(\delta, 500 \mathrm{MHz}, \mathrm{CDCl}_{3}\right): 0.66-0.75(10 \mathrm{H}, \mathrm{m}, \mathrm{Pr}-\mathrm{H}), 1.90-2.02(4 \mathrm{H}, \mathrm{m}$, Pr-H), 4.80 (1H, br, OH), 6.82 (1H, dd, $J=2.0, J=8.0$, Fl-H), 6.85 $(1 \mathrm{H}, \mathrm{d}, J=2.0$, Fl-H), 7.51-7.52 (1H, brm, Fl-H), 7.54 (1H, dd, $J=$ $1.5, J=8.0$, Fl-H), 7.58 (1H, d, $J=8.0, \mathrm{Fl}-\mathrm{H}), 7.67$ (1H, d, $J=8.0$, $\mathrm{Fl}-\mathrm{H}), 7.70$ and 7.75 (4H, $\left.\mathrm{AA}^{\prime} \mathrm{BB}^{\prime}, \mathrm{CF}_{3} \mathrm{Ph}-\mathrm{H}\right) .{ }^{13} \mathrm{C} \mathrm{NMR}(\delta, 100 \mathrm{MHz}$, $\left.\mathrm{CDCl}_{3}\right)$ : 14.4, 17.2, 42.9, 55.4, 110.2, 114.1, 119.2, 120.9, 121.4, $124.4\left(\mathrm{q},{ }^{1} J_{\mathrm{C}-\mathrm{F}}=216\right), 125.6\left(\mathrm{q},{ }^{3} J_{\mathrm{C}-\mathrm{F}}=3\right), 126.1,127.3,128.9(\mathrm{q}$, $\left.{ }^{2} J_{\mathrm{C}-\mathrm{F}}=26\right), 133.6,137.4,141.2,145.2,151.0,153.5,155.6 . \mathrm{m} / \mathrm{z}$ $\left[\mathrm{ESI}^{-}\right]$: expected $409.2\left([\mathrm{M}-\mathrm{H}]^{-}\right)$, found: $409.3\left([\mathrm{M}-\mathrm{H}]^{-}\right)$.

\section{Vapour generation}

TATP vapour was generated using a previously reported setup. ${ }^{\mathbf{1 5}}$ TATP powder $(200 \mathrm{mg})$ was mixed with sand $(10.5 \mathrm{~g})$ and then placed into a glass tube $(\varnothing 0.5 \mathrm{~cm} \times 20 \mathrm{~cm})$. The glass tube was connected to a mass flow controller (MFC) at one end and to a Teflon tube $(\varnothing 2 \mathrm{~mm} \times 20 \mathrm{~mm})$ filled with Amberlyst-15 solidstate acid at the other. The Amberlyst-15 was used to decompose the TATP into hydrogen peroxide and acetone. A second MFC was employed for dilution. Nitrogen was used as both the carrier and dilution gas. The temperature at which the experiments were carried out was $20 \pm 1{ }^{\circ} \mathrm{C}$. The TATP vapour pressure was estimated from the Clausius-Clapeyron equation, $\log _{10} P=19.791-5708 / T$, where $P$ is vapour pressure (pascal) and $T$ is temperature (kelvin). ${ }^{18}$ The TATP vapour concentration was calculated from the dilution factor. The PL response without hydrogen peroxide input was tested in air, rather than in nitrogen, in order to predict the LOD that would be expected under real world usage conditions.

\section{Film preparation}

Films were prepared on planar fused silica substrates by dropcasting from solution. The typical solution comprised $2 \mathrm{mg}$ of boronate ester sensing material and, tetra- $n$-butylammonium hydroxide (6 equiv.) in ethanol $(0.20 \mathrm{~mL})$. The solutions comprising of 1 or 2 were stirred at room temperature in a $1 \mathrm{~mL}$ vial for $10 \mathrm{~min}$ before use. The coatings were fabricated by dropcasting the solution on the substrate at a loading amount of 5 $\mu \mathrm{L} \mathrm{cm} \mathrm{cm}^{-2}$ and then drying under a nitrogen stream for $5 \mathrm{~min}$ followed by placing in a vacuum for $10 \mathrm{~min}$.

\section{Photophysical measurements}

Solution photoluminescence spectra and intensity were recorded on an Horiba Jobin-Yvon Fluoromax 4. Solution photoluminescence quantum yields (PLQYs) were measured by a relative method using quinine sulfate in $0.5 \mathrm{M}$ sulfuric acid, which has a PLQY of 0.55 , as a standard..$^{19}$

\section{Sensing measurements}

The sensing film samples on fused silica substrates were mounted in a sample cell in a fluorometer (Jobin-Yvon Fluorolog 3). The sample cell possessed three optical windows to allow for excitation of the films and subsequent detection of the film PL at right angles to the excitation. The gas mixture containing diluted $\{\mathrm{TATP}\}$ was directed onto the sample at a flow rate of 500-1000 $\mathrm{mL} \mathrm{min}^{-1}$, controlled using two MFCs. Film PL spectra before and after exposure to $\{$ TATP $\}$ were recorded. The PL kinetics at the emissive peak were measured with an excitation wavelength at the absorption peak of the corresponding phenoxides.

\section{Conflicts of interest}

There are no conflicts of interest to declare.

\section{Acknowledgements}

PES is supported by an Advance Queensland Research Fellowship. PLB is an Australian Research Council Laureate Fellow (FL160100067). This research was supported by funding from the Australian Research Council under the Discovery Program (DP130102422).

\section{References}

1 J. J. Sabatini and K. D. Oyler, Crystals, 2016, 6, 5.

2 National Academies of Sciences, Engineering, and Medicine, Reducing the Threat of Improvised Explosive Device Attacks by Restricting Access to Explosive Precursor Chemicals, The National Academies Press, Washington, 2018, DOI: 10.17226/24862.

3 P. E. Shaw and P. L. Burn, Phys. Chem. Chem. Phys., 2017, 19, 29714-29730.

4 X. Sun, Y. Wang and Y. Lei, Chem. Soc. Rev., 2015, 44, 80198061.

5 Y. Salinas, R. Martinez-Manez, M. D. Marcos, F. Sancenon, A. M. Costero, M. Parra and S. Gil, Chem. Soc. Rev., 2012, 41, 1261-1296. 
6 S. W. Thomas, G. D. Joly and T. M. Swager, Chem. Rev., 2007, 107, 1339-1386.

7 R. Schulte-Ladbeck, P. Kolla and U. Karst, Analyst, 2002, 127, 1152-1154.

8 R. Schulte-Ladbeck, P. Kolla and U. Karst, Anal. Chem., 2003, 75, 731-735.

9 S. Malashikhin and N. S. Finney, J. Am. Chem. Soc., 2008, 130, 12846-12847.

10 S. Girotti, E. Ferri, E. Maiolini, L. Bolelli, M. D'Elia, D. Coppe and F. S. Romolo, Anal. Bioanal. Chem., 2011, 400, 313-320.

11 J. Chen, W. Wu and A. J. McNeil, Chem. Commun., 2012, 48, 7310-7312.

12 H. Lin and K. S. Suslick, J. Am. Chem. Soc., 2010, 132, 1551915521.
13 J. Chan, S. C. Dodani and C. J. Chang, Nat. Chem., 2012, 4, 973-984.

14 X. Chen, F. Wang, J. Y. Hyun, T. Wei, J. Qiang, X. Ren, I. Shin and J. Yoon, Chem. Soc. Rev., 2016, 45, 2976-3016.

15 S. Fan, J. Lai, P. L. Burn and P. E. Shaw, ACS Sens., 2019, 4, 134-142.

16 M. Xu, J.-M. Han, Y. Zhang, X. Yang and L. Zang, Chem. Commun., 2013, 49, 11779-11781.

17 A. Liedtke, M. O'Neill, A. Wertmöller, S. P. Kitney and S. M. Kelly, Chem. Mater., 2008, 20, 3579-3586.

18 J. C. Oxley, J. L. Smith, K. Shinde and J. Moran, Propellants, Explos., Pyrotech., 2005, 30, 127-130.

19 J. N. Demas and G. A. J. Crosby, J. Phys. Chem., 1971, 75, 9911024. 